\title{
CALIFORNIA SPANISH FOLKLORE RIDDLES
}

\author{
Aurelio M. Espinosa
}

7 he California Spanish riddles are for the most part old and traditional.

1 Thirty-nine of our [forty-nine] have the same or nearly the same versions in one or more well-known collections of riddles published in Spain and Spanish America. For the remaining [ten] riddles, 22 percent, I have not found parallel versions, but some of these have also the traditional types of verse forms.

The California Spanish riddles have been transcribed in the standard Spanish orthography. For the outstanding characteristics of California Spanish, as it was spoken by Californians of the region extending from Monterey to Santa Barbara twenty-five years ago, when our riddles and other folklore materials were collected, see my article, "Spanish Folktales from California," Hispania, XXIII (1940), 121-144, specially p. 145.

1. Adivíname ésa. - Mesa.

2. Arca, monarca de buen parecer, que no hay carpintero que la pueda hacer, sino sólo Dios con su gran poder. - Cuerpo.

3. Arriba del cielo está una botella; de día se juntan, de noche se desparraman. - Estrellas.

4. Blanco salí de mi casa $y$ en el campo enverdeci;

blanco me volví a meter, conforme como salí. - Maíz.

5. Cajita de ron de China, que la abren y no rechina. - Ojo.

6. Calabaza bolboraza, llena de bolboración, con el casco de calabaza y las uñas de león. - Tortuga. 
7. Cimiento sobre cimiento, sobre el cimiento una caja; sobre la caja dos velas, sobre las velas un monte y sobre el cimiento el ganado. - Persona con piojos.

8. Cuando tengo agua tomo vino y cuando tengo vino tomo agua. - Molinero.

9. Chin chin por los rincones, tú de puntillas y yo de talones. - Escoba.

10. De espinas estoy vestida $y$ es tan grande mi virtud, que al sano causo alegría y al enfermo doy salud. - Rosa de Castilla.

11. Donde me ven me dicen algo y en mi lugar me dicen don. - Algodón.

12. En alto vive, en alto mora; sin ser reina tiene corona. - Granada.

13. En un aposento oscuro cardenales vide estar, todos en grande apretura y cada uno en su lugar. - Granada.

14. En un llano está Mariano, con tres patas y una mano. - Metate.

15. En un llano no muy llano está un anciano, que con un diente recoge a toda su gente. - Campana.

16. En un llano no muy llano está una mujer sin brazos; pa comerle el corazón le hacen el cuerpo pedazos. - Sandía.

17. En una sala cuadrada, llena de mil maravillas, está el penitente sentado y el confesor de rodillas. - Iglesia. 
18. Entre medio de dos piedras

está una niña encerrada;

que llueva o no llueva

siempre está mojada. - Lengua.

19. Entre medio de tres piedritas

saltan y brincan las pajaritas. - Esquite.

20. Entre pader y pader está una ollita con miel - Panal de miel.

21. Es blanco y no es papel, es verde y no es limón;

es colorado y no es sangre,

es prieto y no es carbón. - Mora

22. Es un hombre al parecer que del aire se mantiene; cuerpo tiene, carne no, porque su carne soy yo, de la que su cuerpo tiene. - Sombra.

23. Espinas, pero no de pescado; olas, pero no del mar. - Cebada verde en el campo.

24. Fuí a tu casa y truje de ellas; vine a mi casa lloré con ellas. - Cebollas.

25. Fuî a una güerta y corté de ella; me vine a mi casa y lloré con ella. - Cebolla.

26. Fuí al campo y corté de ella; vine a mi casa y colié con ella - Escoba de ramas.

27. Garra, pero no de cuero; pata, pero no de vaca. - Garrapata.

28. Isla, pero no del mar; bon, pero no jabón. - Islabón (Eslabón).

29. Largo y angosto y amartillau. - Camino

30. Llano blanco, semilla negra, cinco arados y el que la siembra. - Escritor, cinco dedos, pluma y tinta.

31. Mi tío Juan va, mi tío Juan viene; mi tia Mariquita muy honda se mantiene. - Pozo y baldes. 
32. Pelitos por fuera, pelitos por dentro; alza la pata y métela adentro. - Media.

33. Peludito por fuera, peludito por dentro; alza el pie y mételo adentro. - Media.

34. Pintito es; blanquito es; anda y no tiene pies. - Carta.

35. Pinto, paredes blancas y amarillo el corazón. - Huevo de pavo.

36. Por gusto de las mujeres les rompen el cuero, y se quedan pendientes del abujero. - Arracadas.

37. Redondito y redondón, que no tiene tapa ni tapón. - Anillo o calabaza.

38. Sala barrida, patio regado, salió un negrito muy empinado. - Pinacate (escarabajo).

39. Santa soy sin ser nacida, santa sin ser bautizada; santa de la Madre Iglesia, muy santa y santificada. - Semana santa.

40. Siempre que quieren que cante, me ponen boca arriba y me rascan la barriga. - Guitarra.

41. Soy la redondez del mundo; sin mí no puede haber Dios; papas y cardenales sí, pero pontífices no. - Letra $O$.

42. Tú en cuatro patas, yo de rodillas, y en la barriga te hago cosquillas. - Ordeñar la vaca.

43. Un redondón y doce redonditos, el mete y el saca y el bailador. - Horno, pan y palanca.

44. Una casa con cien ventanas y en cada ventana cien viejos. En cada viejo cien bolsas y en cada bolsa cien pesos. - Cien millones de pesos. 
45. Una noche no muy noche, al punto de medio día, se puso a escribir un ciego lo que un mudo le decía, y un sordo lo estaba oyendo, al punto de medio día. - Nada.

46. Una vieja muy caliente que arregla bien a toda su gente. - Plancha.

47. Uno sus vacas vendió, las vendió con gran fortuna, y le dieron por cada una pesos como vacas dió.

Número y cuenta perdió y sólo a decir se atreve que ciento sesenta y nueve pesos de ellas recibió - Trece vacas, a trece pesos cada una.

48. Vengo de tierras morenas, tengo por padre un cantor, con mis habititos blancos y amarillo el corazón. - Huevo.

49. Ya ves cuan claro es. Adivínamelo si lo sabes. - Llaves. 
